\title{
LOS PRINCIPIOS FORMATIVOS EN LOS PROCEDIMIENTOS ORDINARIOS DEL TRABAJO
}

\author{
MARIO CARVALLO VALLEJOS \\ Abogado, Profesor Titular \\ Escuela de Derecho - U.C.N. Coquimbo
}

Los abogados y académicos laboralístas vemos frecuentemente, al enfocar el tema del procedimiento laboral, que se suele hacer fuertemente inspirado en los rigores de la formación civilista. Abogados patrocinantes y procuradores no logran penetrar con profundidad en la ratio legis del proceso laboral; no capitalizan el sentido de la ley procedimental para formular sus estrategias jurídicas en el foro. Nos parece, creo, que apenas se divisan asomos, justificados quizás por la falta de profundización en la cátedra, respecto de la aplicación de aquellos principios superiores y permanentes que inspiran el procedimiento laboral. El mismo fenómeno se observa, con diferentes acentos, en materia de derecho de fondo.

Aceptando una honrosa invitación de la Escuela, he creído conveniente desarrollar un esquema sobre los principios formativos del procedimiento en los juicios ordinarios del trabajo, que sirva de pie para despertar la atención de los alumnos y abogados que sienten curiosidad por esta disciplina.

Al introducir este trabajo, conviene tener presente, en cuanto a las normas particulares que gobiernan la substanciación o ritualidad de los procedimientos del trabajo, que entre nosotros existen el procedimiento ordinario Ilamado "de aplicación general", comprendido en el Párrafo $2^{\circ}$ del Capítulo II del Título I del Libro V del Código del Trabajo, y el procedimiento ordinario llamado "de menor cuantía", comprendido en el Párrafo siguiente.

Además, consignemos desde luego que en materia laboral existen otros procedimientos, pero de carácter especial, que no serán abordados en este trabajo, por ahora ${ }^{122}$ 123

${ }^{122}$ El juicio laboral de menor cuantía aparece regulado en el artículo 459 del Código del Trabajo, incorporado a nuestro sistema procesal por el artículo $3^{\circ} N^{2} 20$ de la Ley $N^{\circ}$ 19.250.-

${ }^{123}$ Podemos anotar entre los procedimiento especiales de carácter laboral, los referentes a la reclamación por infracción al caso de ius variandi del artículo 12 del Código del Trabajo; procedimiento ejecutivo de aplicación general, a que se refieren los artículos 460,461 y 462 del mismo Código; el procedimiento arbitral contenido en los artículos 355 a 368, referido a la negociación colectiva; el procedimiento sobre infracciones por prácticas desleales a que se refieren los artículos 292 y 389 , referido a organizaciones sindicales y negociación colectiva; procedimiento judicial en negociación colectiva referido en los artículos 391 a 396; procedimiento de disolución de organizaciones sindicales a que se refiere el artículo 297; procedimiento ejecutivo especial contemplado 
Los procedimientos ordinarios se abocan a solucionar conflictos de carácter jurisdiccional, de la esfera del derecho del trabajo y de la seguridad social, tanto en el ámbito de las relaciones entre empleadores y trabajadores, sea de derecho colectivo como de derecho individual, e incluso puede llegar a encontrarse un juez conociendo y resolviendo materias relativas a trabajadores independientes, esto es, aquellos que en su desempeño laboral no dependen de empleador alguno ni son tampoco empleadores ellos ${ }^{124} 125$.

La normativa que regula las grandes directrices de los procedimientos en estudio es el Código del Trabajo, quedando la aplicación de la legislación procedimental civil en carácter de supletoria, habida consideración previa de ser el procedimiento ordinario del trabajo de aplicación general supletorio de los restantes procedimientos laborales.

Observaremos a primera vista que nuestra legislación procesal del trabajo se encarga de regular lo orgánico y lo funcional ${ }^{126}$, lo que se explica por la tendencia codificadora de los tiempos modernos, constante que venimos observando desde el siglo pasado, y que pretende evitar la dispersión de cuerpos legales y simplificar su manejo. Hacemos hincapié en que ello se observa especialmente en la codificación de las reglas substantivas en un mismo cuerpo con las reglas adjetivas o procesales, quedando a nuestro juicio inconclusa la labor codificadora de la legislación sobre previsión social, que entendemos justificada por razones de política legislativa que no es necesario abordar en este trabajo, pero estimamos no obstante que estamos en tal aspecto en un período de transición, sentando las bases para una futura codificación ${ }^{127} 128$.

en la Ley $N^{2} 17.322$ sobre cobranza de cotizaciones, aportes y multas de las instituciones de previsión. Incluso, podemos anotar una norma meramente programática, que nunca entró en práctica, relativa al único caso de arbitraje que conoce nuestro derecho individual del trabajo, y que consagró el Tribunal Arbitral del Fútbol Profesional, señalado en el D.F.L. No 1, de 1970, del Ministerio de Defensa Nacional, denominado "Estatuto de los Deportistas Profesionales".

124 Para los efectos de esta afirmación, no vamos a asumir la decantanción que hace la doctrina de la relativa dualidad y autonomía que existiría entre las disciplinas del Derecho del Trabajo y del Derecho de la Seguridad Social, que incluso ha llegado a afirmar que, no obstante la filiación histórica que existe entre ellas, actualmente estaríamos frente a dos disciplinas con identidades independientes.

125 Como ejemplo, podemos señalar el conocimiento de la reclamación judicial en contra de las observaciones administrativas que puede efectuar la respectiva Inspección del Trabajo a la constitución de un sindicato de trabajadores independientes, o a sus estatutos. Ver incisos tercero y cuarto del artículo 223이 Código del Trabajo.

${ }^{126}$ El texto refundido, coordinado y sistematizado del Código del Trabajo vigente fue fijado por D.F.L. № 1, de 7 de enero de 1994, publicado en el Diario Oficial de fecha 24 de enero de 1994.

127 Sobre este tema, ver "El Nuevo Régimen Previsional y de Cotizaciones". William Thayer Arteaga y Eduardo Fernández Flores. Editorial Jurídica de Chile. 1981.

${ }^{128}$ Se observa un claro intento en unificar los regímenes previsionales y de seguridad social, tanto desde el punto de vista de las cotizaciones, de las prestaciones y de los órganos de gestión. La reforma previsional implementada desde el año 1981, inspiradora de otras reformas similares en el extranjero, estableció el régimen de Administradoras de Fondos de Pensiones, creó el Instituto de Normalización Previsional y creó un sistema de ajuste entre el régimen antiguo y el nuevo, tendiente a substituir 
Pretendemos en estas líneas señalar los grandes fundamentos doctrinarios que han condicionado el surgimiento de las especiales características del procedimiento laboral, que se nutre de la singular presencia de los principios formativos del procedimiento. Pretendemos también estudiar cómo el procedimiento común u ordinario del trabajo recoge la influencia de dichos fundamentos o principios.

Es punto pacífico en la doctrina el estimar que la justicia debe ser rápida, económica y segura. La manera en que esos objetivos deben ser alcanzados es opinable.

La celeridad de los procedimientos exige reglas simples para las tramitaciones judiciales, concentración de las actuaciones y restricción de los recursos. La economía, en donde encontramos inserta la celeridad, exige que obtengamos la mayor calidad en los resultados del proceso, con la aplicación del mínimo de tiempo y de esfuerzos. Por su parte, la seguridad jurídica presupone la imparcialidad del tribunal, la rectitud del fallo, el respeto al debido proceso y la estabilidad de las resoluciones.

A la hora de diseñar uno o varios sistemas en un determinado marco jurídico, que nos permita llevar a cabo estos propósitos, los legisladores difieren en la manera de encarar el problema.

Este fenómeno tiene relación con la manera de aplicar los principios formativos del procedimiento. En el ámbito del derecho procesal del trabajo, además, observamos con perspectiva histórica cómo difiere esta política legislativa, adoptando una determinada graduación, concorde con el pensamiento imperante en el momento político social que se viva.

La posibilidad de graduación en la aplicación de estos principios se debe a que éstos son generalmente bipolares, de modo que a cada uno de ellos se le opone otro contrario. La distancia en que se posicione el derecho procesal laboral respecto de los principios formativos del procedimiento es relativa, dependiendo de los énfasis que imprima el legislador.

No existe la aplicación absoluta de un determinado principio, o de su opuesto, en los distintos procedimientos, porque cualquiera sea el que se adopte, se admitirán múltiples excepciones que morigeran su aplicación irrestricta.

Hemos estimado pertinente exponer una síntesis de algunos de estos principios, atendidas razones de espacio, y comentar su aplicación en los procedimientos laborales que nos ocupan.

\section{LOS PRINCIPIOS DISPOSITIVO E INQUISITIVO}

El primero es aquel en que se entrega a las partes la actividad del proceso, de modo que son éstas las que deben impulsar la actividad jurisdiccional, éstas deben aportar el material de convencimiento al juez.

aquel por éste último, bajo la doctrina de la subsidiaridad del Estado y la integración armónica del sistema previsional con el sistema financiero, a través de la capitalización de los fondos previsionales destinado a pensiones, ahora de propiedad privada. 
En cuanto a la iniciativa del proceso, sólo puede comenzar a instancia de parte, de modo que la parte interesada se encuentra en la necesidad de iniciarlo mediante la interposición de una demanda o de una medida prejudicial. El juez nunca puede iniciarlo de oficio. Es típico del juicio civil, ya que en éste existe la facultad de las partes de disponer de. derechos materiales, salvo cuando con ello se lesionen normas de orden público.

En cuanto al impulso del juicio una vez iniciada la contienda, le está vedado al juez imprimirlo. En consecuencia, el actor no sólo requiere la iniciación del proceso, sino que también tiene que impulsar su secuela a fin de obtener resultados. Por otro lado, corresponde a las partes delimitar la cuestión controvertida. El juez sólo podrá pronunciarse sobre aquello que se le ha pedido por las partes.

En cuanto a la aportación de los hechos, corresponde también a las partes la carga de afirmar hechos, impidiendo que el juez averigüe sobre hechos no aportados por las partes. La prueba debe ser suministrada por las partes, ya que el juez no puede investigar. Prevalece la verdad formal. En nuestro procedimiento civil, este principio se ve atenuado cuando se permite al juez rechazar de oficio algunos incidentes, decretar medidas para mejor resolver, llamar de oficio a las partes a conciliación en cualquier estado de la causa, o casar de oficio una sentencia ${ }^{129}$.

El principio inquisitivo, en cambio, permite al juez iniciar de oficio el proceso, con amplias facultades para impulsar su secuela, investigar acerca de los hechos de la causa, comprobar con amplias facultades la efectividad de esos hechos. El juez desempeña un papel activo. Es el principio típico de la fase sumaria del juicio criminal.

En materia laboral, se nota una gran presencia del principio inquisitivo o de la oficialidad. No obstante, sostenemos que la regla general la constituye la vigencia del principio dispositivo. Sin embargo, la multiplicidad de excepciones en que el legislador hace prevalecer el principio de la oficialidad, caracteriza el perfil especial de la disciplina.

No podemos sostener que el juicio laboral sea per se de orden inquisitivo, de manera que las partes se encuentren liberadas de la obligación de instar por su prosecución y término, ya que la permanencia de los conflictos obsta a la certeza jurídica que tanto los litigantes y la sociedad requieren.

En efecto, en relación al primer punto, esto es, a la iniciativa del proceso, podemos advertir que se requiere la interposición de la demanda del actor, para dar inicio al procedimiento, la que deberá constar por escrito tanto en el procedimiento ordinario de aplicación general como en el de menor cuantía, haciendo aplicable aquí plenamente el principio dispositivo ${ }^{130}$.

En cambio, si estamos a la secuela o impulso del juicio una vez que éste se ha iniciado, el procedimiento laboral asume constantemente elementos del principio de la oficialidad o inquisitivo. Así, por ejemplo, vencido un plazo fatal para evacuar un trámite que es previo para continuar el juicio, y en consecuencia, estando rebelde una parte, corresponde al juez de oficio o a petición de parte, proveer lo que convenga para su

\footnotetext{
${ }^{129}$ Ver artículos 84, 159, 262 y 776 del Código de Procedimiento Civil.

${ }^{130}$ A tal conclusión se llega cuando el artículo 429 del Código del Trabajo señala que la "demanda se interpondrá por escrito".
} 
prosecución ${ }^{131}$. Asimismo, el nombramiento de receptor ad-hoc lo practica el tribunal de oficio, sin necesidad de que exista petición de parte ${ }^{132}$. Puede el juez de oficio corregir los errores que observe en la tramitación del juicio, y tomar las medidas que tiendan a evitar la nulidad de los actos de procedimiento ${ }^{133}$, de modo que le entrega una función preventiva de las nulidades, que puede el juez utilizar por propia iniciativa, motu proprio.

De la misma manera, corresponde al juez instar a las partes para que lleguen a una conciliación, debiendo proponer las bases de arreglo que estime por conducentes a tal efecto, trámite esencial en el comparendo de conciliación y pruebas ${ }^{134}$, cuya ausencia produciría un vicio de casación.

No se requiere que la parte solicite al tribunal la dictación del auto de pruebas si es que existen hechos sustanciales pertinentes y controvertidos, ni tampoco para que el tribunal fije día y hora para verificar el comparendo de conciliación y pruebas, toda vez que el legislador señala al juez la obligación de que, contestada que sea la demanda, de no interponerse reconvención o excepciones dilatorias, o evacuado el traslado conferido, de haberse interpuesto éstas, o vencido el término legal para ello sin haberse contestado, el tribunal recibirá de inmediato la causa a prueba, fijará los puntos sobre los cuales ésta deberá recaer y resolverá sobre las diligencias de prueba que hubieren solicitado las partes.

Lo mismo ocurre en cuanto al procedimiento laboral de menor cuantía. Acá basta la presentación de la demanda para que el juez quede obligado a citar a las partes a un comparendo de discusión, conciliación y pruebas, sin previa petición de parte.

La citación para oír sentencia también es una resolución que el tribunal debe dictar de oficio. Si se rindieron pruebas, la dictará vencido el término de cinco días para efectuar las observaciones que ellas hayan merecido a las partes. Si no fue recibida la causa a prueba por no considerarse que existan hechos substanciales pertinentes y controvertidos, entonces el tribunal la dictará una vez que se haya verificado el comparendo de conciliación, siempre que la conciliación no se haya producido.

Si el procedimiento fuere de menor cuantía, esta resolución la dictará de oficio terminada la recepción de las pruebas, en el comparendo de discusión, conciliación y pruebas, o dentro de tercero día.

En primera instancia se manifiesta el principio de la oficialidad a la hora de determinar los hechos sobre los que ha de versar el juicio, puesto que éstos se derivan de los escritos fundamentales que fijan la litis, generalmente la demanda y la contestación. El juez sólo podrá pronunciarse en su fallo sobre tales hechos y no otros.

Conviene acotar, asimismo, que la interposición de recursos procesales corresponde a las partes.

De igual forma, las nulidades de oficio que pueda decretar el tribunal no se relacionan con recursos, puesto que los recursos, por definición, corresponden a impugna-

\footnotetext{
131 Ver parte final del inciso primero del artículo 429 del Código del Trabajo.

${ }^{132}$ Ver inciso segundo del artículo 430 del Código del Trabajo.

${ }^{133}$ Ver artículo 437 del Código del Trabajo.

${ }^{134}$ Ver inciso primero del artículo 444 del Código del Trabajo.
} 
ciones hechas por las partes en contra de una determinada resolución judicial, lo que no ocurre en la especie.

En relación a la aportación del material probatorio, corresponderá a las partes según las reglas generales. Sin embargo, tal como hemos advertido, en el procedimiento laboral interesa más la verdad material que la verdad formal, de lo que se sigue que se autorice al juez no sólo a dictar medidas para mejor resolver, sino además considerar en su sentencia, por la vía de apreciar las pruebas conforme a las reglas de la sana crítica, no sólo las pruebas tradicionales sino cualquier elemento de convencimiento que obre en el proceso $^{135}$.

En segunda instancia, domina el principio dispositivo, conforme a las reglas generales del alzamiento en lo civil.

La prevalencia del principio dispositivo en los procedimientos se observará siempre cuando el derecho material que se discute es disponible, reconociéndose la vigencia de los principios que rigen los derechos subjetivos o de fondo, como el de la autonomía de la voluntad. En cambio, si se comprometen normas de orden público, prevalecerá el principio de la oficialidad, que permite un mayor gobierno del proceso por parte del juez.

Como hemos visto, en materia laboral existen mayores normas de orden público que en materia civil.

\section{AUDIENCIA \\ II. EL PRINCIPIO DEL CONTRADICTORIO O DE LA BILATERALIDAD DE LA}

Este principio tiene jerarquía constitucional, toda vez que la Carta Fundamental establece que corresponde al legislador establecer siempre las garantías de un racional y justo procedimiento ${ }^{136}$. La esencia del debido proceso puede resumirse en la necesidad en que se encuentran el juez de oír a ambas partes, de manera que éste no puede decidir acerca de una pretensión si la persona en contra de la cual ha sido propuesta esa pretensión no ha tenido la oportunidad de ser oída, en un plazo prudente. Se requiere de una suficiente y racional posibilidad de ser oído y de producir pruebas.

Este principio está significativamente presente en materia de procedimiento civil, e igualmente, en los procedimientos laborales, en todo el desenvolvimiento de la causa, salvas algunas restricciones excepcionales como las medidas prejudiciales precautorias y en el despacho del mandamiento de ejecución y embargo en juicio ejecutivo, que también vemos presentes en materia civil.

Se consulta en el procedimiento laboral que, interpuesta la demanda del actor, se confiere traslado al demandado para que conteste por escrito, por el término fatal de diez días, aumentados conforme a la tabla de emplazamiento. Si el demandado reconviene u opone excepciones dilatorias, se confiere traslado por el término de cinco días al actor para que conteste unas y otras.

135 Conforme al artículo 456 del Código del Trabajo, al apreciar el sentenciador las pruebas conforme a la sana crítica, tomará en especial consideración las características de las pruebas rendidas "o antecedentes del proceso que utilice...".

${ }^{136}$ Ver artículo 19 № $3^{\circ}$ inciso 5ํ de la Constitución Política del Estado. 
La bilateralidad de la audiencia se cumple con el sólo hecho de dar la posibilidad al contradictor de ser oído, aunque éste no haga nada por su parte en beneficio de su defensa, puesto que su rebeldía no lesiona el cumplimiento de este principio. Asimismo, el litigante rebelde en la contestación de la demanda, o de las excepciones dilatorias, o de la reconvención, según el caso, no tiene inconveniente en participar en el suministro de pruebas que lo favorezcan, o de incorporarse activamente en cualquier estado de la causa, siempre que se someta a la ritualidad establecida para rendirlas ${ }^{137}$.

\section{EL PRINCIPIO DE LA ECONOMIA PROCESAL}

Este es un principio amplio que comprende todas las posibilidades que tiendan a la abreviación del procedimiento, para economizar gastos y esfuerzos, logrando así mayor celeridad en su conclusión, de manera de no comprometer la justicia oportuna.

La presencia de disposiciones tendientes a la economía procesal, en materia de juicios del trabajo, es bastante significativa, y constituye en realidad uno de los pilares básicos de esta clase de procedimientos. enfoque:

Se distinguen ciertas variantes a este principio, dependiendo de la perspectiva de su

\section{a) El Principio de la Concentración}

Este principio propende a reunir toda la actividad procesal en la menor cantidad posible de actos, a fin de evitar que esa actividad se disperse. No se refiere a la supresión de actuaciones, sino a que éstas se verifiquen, pero de forma concentrada.

Entre otros, nuestro procedimiento sumario en materia civil representa un esfuerzo de concentración de los actos procesales, desde el momento en que, presentada la demanda, se convoca a una audiencia al quinto día hábil a contar de la notificación al demandado, en el que se verificará un comparendo destinado a que el demandado haga valer todas sus alegaciones, defensas y excepciones; $y$, con el mérito de ello, el juez resuelve el asunto o recibe la causa a prueba. Los incidentes deben promoverse y tramitarse en esa misma audiencia, conjuntamente con la causa principal.

En el procedimiento laboral de aplicación general anterior al vigente, recientemente modificado, se establecía que, contestada la demanda o la reconvención en su caso, o transcurrido el término para hacerlo, el tribunal debía de inmediato y sin más trámite, citar a las partes a una audiencia para un día no inferior al quinto ni superior al decimoquinto, con el objeto de procurar la conciliación. Si esta conciliación no se producía, en la misma audiencia recibía la causa a prueba y fijaba los puntos sobre los que ella debía recaer y, en la misma resolución, citaba a un comparendo de pruebas que no podía verificarse antes de cinco días ni después de diez días contados desde la fecha de la resolución. Terminada la recepción de las pruebas y no existiendo diligencias pendientes, el tribunal citaba a las

${ }^{137}$ No rige en materia laboral la sanción aplicada a quien no se hace parte en segunda instancia en el término legal, por cuanto, como se ha explicado, las partes se encuentran emplazadas en segunda instancia desde que se les notifica la resolución que concede el recurso. Ver artículo 202 del Código de Procedimiento Civil. 
partes a oír sentencia. Lo mismo decretaba si en el comparendo de conciliación ésta no se acordaba, sin existir hechos substanciales, pertinentes y controvertidos.

Las normas en actual rigor, concentran más aún el procedimiento de aplicación general, y -además- crean un procedimiento de menor cuantía de carácter sumarísimo.

En efecto, hoy, contestada que sea la demanda, de no interponerse reconvención o excepciones dilatorias, o evacuado el traslado conferido, de haberse interpuesto éstas, o vencido el término legal para ello sin haberlas contestado, el tribunal recibirá de inmediato la causa a prueba, fijará los puntos sobre los cuales ésta deberá recaer y resolverá sobre las diligencias de prueba que hubieren solicitado las partes.

Hay que advertir que ahora la demanda puede contener solicitudes de diligencias probatorias, las que son resueltas por el tribunal en la misma resolución que recibe la causa a prueba.

Esta misma resolución también cita a las partes a comparendo de conciliación y pruebas para un día no anterior al octavo ni posterior al decimoquinto, contados desde la fecha de notificación de la resolución.

El principio de la concentración aparece con mayor agudeza en el procedimiento laboral de menor cuantía, cuya característica es el de ser sumarísimo, y en el que se establece que, presentada la demanda, el tribunal cita a las partes a una audiencia de discusión, conciliación y pruebas, a la que deben éstas recurrir con todos sus medios de prueba, a celebrarse dentro de los diez días siguientes. Si no se produce conciliación, en esa misma audiencia el tribunal recibe todas las pruebas que las partes en tal acto ofrezcan. Una vez recibida las pruebas, el tribunal cita a las partes para oír sentencia, que puede dictar en el mismo acto o dentro de tercero día.

Observemos que en el procedimiento someramente descrito, en un único comparendo se discute, se insta a conciliación, se prueba, se puede citar a las partes a oír sentencia y se puede dictar la sentencia. No existiría inconveniente alguno en que se notifique en ese acto el fallo por el secretario, si es que las partes no se dan por notificadas de ella en el mismo comparendo.

En segunda instancia, la tramitación es indistinta, tratándose del procedimiento de aplicación general o procedimiento de menor cuantía.

Con anterioridad a la vigencia de la Ley № 19.250, de 30 de septiembre de 1993, la apelación se sujetaba a las normas del Código de Procedimiento Civil para la apelación de los incidentes, con algunas variaciones. Hoy, la apelación se sujeta a la tramitación general, con variaciones que el Código del Trabajo se encarga de señalar, pero que son destinadas a dar mayor celeridad al proceso, más que a evitar actuaciones. En este último sentido, observemos que no es necesario que las partes comparezcan en segunda instancia.

\section{b) Principio de la Eventualidad}

Este principio promueve que todas las alegaciones que desee formular una parte, sean planteadas simultáneamente, en forma conjunta; o unas en subsidio de las otras, con el objeto de evitar el planteamiento sucesivo de excepciones, alegaciones y defensas, que dilatarían el juicio. 
Resulta conveniente advertir que, mientras el principio de la concentración se refiere a las actuaciones procesales, el principio de la eventualidad se refiere a las alegaciones en juicio.

El principio en análisis se aplica entre nosotros, en materia civil, por ejemplo, en la necesidad de plantear las excepciones dilatorias en un mismo escrito ${ }^{138}$; en la necesidad de plantear el recurso de apelación en subsidio del recurso de reposición o conjuntamente con el de casación ${ }^{139}$; en los casos de pluralidad de acciones ${ }^{140}$.

En materia laboral, la contestación de la demanda deberá contener todas las excepciones dilatorias y perentorias y la exposición de los hechos en que se funden. El legislador es expreso en orden a establecer que, con posterioridad a la contestación, no podrá hacerse valer excepción alguna ${ }^{141}$.

En materia civil, en cambio, la oposición de excepciones dilatorias, todas en un mismo escrito, debe efectuarse antes de contestar la demanda. Es más, una vez desechadas las excepciones dilatorias, o subsanados por el demandante los defectos de que adolezca la demanda, tiene el demandado diez días para contestar la demanda ${ }^{142}$.

\section{c) Principio de la Celeridad}

Con este principio se pretende que las actuaciones procesales sean ejecutadas en los plazos lo más restringidos posible.

La celeridad de los procedimientos se obtiene, principalmente, por el establecimiento de los plazos fatales, por el acortamiento de los plazos, por la preferencia para que la causa quede en tabla, que, unida a las medidas tendientes a concentrar los procedimientos, se llega a una mayor economía procesal.

No es lo mismo suprimir un trámite, que concentrarlos con otros, porque, en el segundo caso, el trámite se verifica y, en el primero, no existe. Es por eso que la supresión de actuaciones mira al principio de la celeridad y no al principio de la concentración.

En efecto, hoy todos los plazos son fatales ${ }^{143}$, de modo que es innecesario acusar la rebeldía y declararla, para que precluya la posibilidad de evacuar el trámite pendiente para proseguir el juicio. Basta ahora el transcurso del plazo para que pueda seguirse adelante en la substanciación del procedimiento.

Es sabido que el demandado civil tiene un plazo de quince días, más el aumento del término de emplazamiento, para contestar la demanda. En el juicio ordinario del trabajo de aplicación general y en el de menor cuantía, este plazo se ve disminuido a diez días.

\footnotetext{
${ }^{138}$ Ver artículo 305 del Código de Procedimiento Civil.

139 Ver artículos 188 y 770 inciso segundo del Código de Procedimiento Civil.

140 Ver artículo 17 del Código de Procedimiento Civil.

${ }^{141}$ Ver inciso tercero $N^{\circ} 3$ del artículo 440 del Código del Trabajo.

142 Ver artículo 308 del Código de Procedimiento Civil.

${ }^{143}$ Ver artículo 64 del Código de Procedimiento Civil, substituido por la Ley No 18.882, de 20 de diciembre de 1989 .
} 
La fase de discusión en un juicio ordinario civil se puede extender bastante, si sumamos el tiempo necesario para la evacuación de la contestación, réplica y dúplica, a fin de que quede la causa en estado de recibirse a prueba. La supresión de estos trámites constituyen mas bien aplicación del principio de la celeridad, que produce una disminución del tiempo habido entre la contestación de la demanda y la recepción de la causa a prueba, mediante la supresión de trámites y actuaciones procesales.

En nuestro procedimiento laboral de aplicación general, la ley contempla una medida de celeridad expresamente, cuando dispone al juez que vele por este principio al fijar día y hora para la realización de la diligencia de exhibición de documentos que existan en poder de la contraparte 0 de terceros ${ }^{144}$.

Cuando el tribunal despache oficios como medida probatoria de las partes, la ley manda a que sean contestados en el plazo de quince días hábiles siguientes a contar de la recepción, con el objeto de que el plazo no quede entregado a la voluntad del funcionario o persona informante ${ }^{145}$.

\section{d) Principio de la Adquisición}

Este principio sostiene que las actividades desarrolladas en el proceso no sólo benefician a quien las solicitó o ejecutó, sino también pueden beneficiar a la parte contradictora. Tiene mucha importancia en materia de pruebas, puesto que ésta está dirigida y destinada al proceso. Por ejemplo, entre nosotros, lo declarado por el testigo puede beneficiar o perjudicar a quien lo presenta, sin que éste pueda hacer algo, salvo retirar al testigo, pero antes de que deponga.

Otra expresión se nota en materia de absolución de posiciones, en cuanto a que la parte que redacta las posiciones puede declarar ciertos hechos que, si no son controvertidos, los adquiere el proceso aunque lo perjudiquen. Algo similar sucede con los dichos de cualquiera de las partes, expresados a través de sus escritos, en orden a que, por regla general, no se recibe prueba alguna contra hechos personales claramente confesados por los litigantes en juicio.

\section{e) Principio de la Inmediación}

Este principio exige el contacto directo del juez con las partes y con todo el material del proceso, excluyendo cualquier medio indirecto de conocimiento judicial. Se expresa principalmente en la posibilidad que se confiere a las partes para que la confesión judicial sea tomada directamente por el juez, sin intervención de otro funcionario. También se expresa en la inspección personal del tribunal, que también es un medio probatorio.

La aplicación del principio de la mediación en sede laboral se reconoce en las gestiones que el juez realiza para lograr la conciliación. El legislador ordena al juez para que personalmente inste a las partes a acordar la conciliación, sometiendo a consideración de éstas las bases sobre las cuales la estima posible, declarando el legislador expresamente

\footnotetext{
${ }^{144}$ Ver parte final del artículo 447 del Código del Trabajo.

${ }^{145}$ Ver inciso primero del artículo 448 del Código del Trabajo.
} 
que las opiniones que el tribunal emita para instar por la conciliación, no serán causales de inhabilitación ${ }^{146}$.

Asimismo, en esta clase de procedimientos la declaración de testigos es tomada personalmente por el juez, únicamente ante el tribunal que conozca de la causa, de lo que fluye la imposibilidad de que un tribunal, por medio de competencia delegada, pueda recibir la testimonial ${ }^{147}$.

Todas las pruebas deben rendirse en el comparendo de conciliación y pruebas, si se tratare de un juicio ordinario de aplicación general; o en el comparendo de contestación, conciliación y pruebas, si se tratare de un juicio laboral de menor cuantía, audiencias éstas que se verifican necesariamente ante el juez de la instancia.

A este principio se le opone el principio de la mediación, que sustenta que el juez no debe guardar una relación directa con las partes, que su relación debe ser impersonal, a fin de asegurar su objetividad e imparcialidad.

\section{f) Principio de la Preclusión}

Con la aplicación de este principio se crea una verdadera compuerta o esclusa, que impide que, llegada cierta etapa del proceso, se pueda volver atrás.

Es sabido que el proceso está constituido por diversas etapas o fases, estructuradas unas en pos de las otras. La preclusión, en sentido procesal, es una sanción que el legislador aplica al litigante remiso, en términos de que éste no puede evacuar un trámite o ejercer un derecho con posterioridad a la oportunidad que la ley le confiere para hacerlo. El legislador sanciona la inejecución oportuna de un acto procesal.

La preclusión puede operar por vencimiento del plazo, como cuando se impide interponer un recurso fuera del plazo concedido por la ley para hacerlo; o por la realización de un acto incompatible con otro que se pretende realizar, como cuando se contesta la demanda precluye el derecho a oponer posteriormente excepción de ineptitud del libelo; o por la consumación del derecho conferido por la ley, como cuando se apela de una resolución judicial, no podría posteriormente volver a apelar de la misma.

En el procedimiento laboral ordinario de aplicación general se advierte claramente la aplicación de este principio. En efecto, en el mismo escrito en que se presenta la lista de testigos debe solicitarse su citación judicial. Igualmente, si la parte tuviere interés en rendir prueba confesional, rendir prueba pericial, solicitar oficios y cualquier otra diligencia de prueba que la parte no hubiere solicitado en el escrito de demanda o de contestación, debe solicitarlo en aquel escrito. Allí mismo debe acompañarse toda la prueba documental que no se hubiere presentado con anterioridad. El legislador es expreso en señalar que no habrá lugar a prueba ni a diligencia alguna que se solicite con posterioridad ${ }^{148}$.

\footnotetext{
${ }^{146}$ Ver inciso primero del artículo 444 del Código del Trabajo.

${ }^{147}$ Ver inciso primero del artículo $449^{\circ}$ del Código del Trabajo.

${ }^{148}$ Ver inciso final del artículo 443 del Código del Trabajo.
} 
Otra manifestación del principio de la preclusión es la imposibilidad de rendir pruebas en segunda instancia, salvo la instrumental si la parte que la presente justifica haber estado imposibilitada de presentarla en primera instancia ${ }^{149}$.

Por otra parte, vemos presente en el procedimiento ordinario laboral de menor cuantía cierto apartamiento de este principio, aproximándolo a su opuesto, denominado por la doctrina "principio de unidad de la vista" 150 , que polarizado a la máxima expresión, podemos definir como aquel en que en un sólo momento procesal se desarrollan las fases de conocimiento, prueba y sentencia.

En efecto, presentada que sea la demanda en el juicio laboral de menor cuantía, el tribunal cita a las partes a una audiencia de discusión, conciliación y pruebas, a la que las partes deben concurrir con todos sus medios de prueba. En la audiencia, el tribunal escucha a las partes, las insta a una conciliación y, de no producirse ésta, recibe en ese mismo acto todas las pruebas que ofrezcan las partes y que sean atingentes con el asunto controvertido. Terminada la recepción de las pruebas, el tribunal cita a las partes a oír sentencia, la que incluso puede dictar en ese mismo acto, o dentro de tercero día ${ }^{151}$.

\section{EL PRINCIPIO DE LA PUBLICIDAD}

Este principio requiere que los actos procesales sean presenciados o conocidos, incluso por quienes no son partícipes en ese proceso ${ }^{152}$, salvas las excepciones legales, como por ejemplo, la reserva en el juicio de nulidad de matrimonio ${ }^{153}$, los acuerdos de los tribunales colegiados y los sumarios criminales. La aplicación de este principio en materia laboral no difiere de las reglas dadas para el procedimiento civil, de lo que es dable concluir que en los juicios laborales es improcedente decretar el secreto de la causa, salvo en lo referido al la reserva del acuerdo en segunda instancia.

\section{LOS PRINCIPIOS DE LA ORALIDAD Y DE LA ESCRITURACION}

El principio de la oralidad se encuentra íntimamente vinculada a los principios de la inmediación, de la concentración y de la inmutabilidad del juez de la instancia. Se concilia más con los procedimientos de única instancia.

Los tratadistas se inclinan por uno u otro de estos principios, encontrando ventajas y desventajas en ambos. Los partidarios de la oralidad lo admiran por su celeridad, concentración, mayor publicidad y mediación del juez. Se estima que favorece la dirección y gobierno del proceso por el juez. Los proclives al proceso escrito dicen que la práctica de la oralidad no es garantía de celeridad. La escrituración permite mayor ponderación por parte

\footnotetext{
${ }^{149}$ Ver artículo $469^{\circ}$ del Código del Trabajo.

${ }^{150}$ Ver Hugo Herrera Cárdenas. "Principios formativos de los Procedimientos Laborales Chilenos". Memoria de Prueba. Escuela de Derecho. U. de Chile. Sin indicación de año.

${ }^{151}$ Ver letras a) y c) del artículo 459 del Código del Trabajo.

152 Ver artículo 9 del Código Orgánico de Tribunales.

${ }^{153}$ Ver artículo 756 del Código Orgánico de Tribunales.
} 
de los litigantes y mayor objetividad por parte del juez. Se eliminan los riesgos de la retórica u oratoria forense, que la mayor de las veces tienen más bien un propósito efectista.

Por lo demás, en nuestro medio, la experiencia ha demostrado que abogados y jueces evitan la oralidad incluso cuando está permitida por el procedimiento, como en el caso del procedimiento sumario, sumarísimo y otros del mismo carácter ${ }^{154}$, aspecto a considerar en las discusiones y proposiciones legislativas en orden a instaurar en materia penal el proceso oral en nuestro país.

\section{EL PRINCIPIO DE LA BUENA FE}

Este principio aparece establecido expresamente en la ley en diversas disposiciones. Sostiene que las partes y sus defensores tienen el deber de conducirse en juicio con lealtad y propiedad, principio a veces transgredido por las pasiones y desorientaciones de las partes, e incluso, y lo que resulta doblemente lamentable, de sus abogados.

El principio de la buena fe se traduce, por ejemplo, en materia de prueba en el juicio civil de mínima cuantía, en que el legislador permite al juez apreciar la prueba en conciencia, atendiendo a la impresión que la haya merecido la conducta de las partes durante el juicio y la buena o mala fe con que hayan litigado en él ${ }^{155}$. También lo encontramos en materia de abuso de incidentes cuando éstos son temerariamente interpuestos ${ }^{156}$, o como causal del recurso de revisión ${ }^{157}$.

No vemos inconveniente en que sea considerada la buena fe con que hayan litigado las partes a la hora de dictar el fallo laboral en un juicio de menor cuantía, toda vez que se concilia con la apreciación de las pruebas en conciencia que rige en este procedimiento, y no se divisa obstáculo para aplicar la misma norma que rige en el juicio civil de mínima cuantía.

Por otro lado, en sede laboral rige plenamente la sanción al articulista temerario, a que se refiere el artículo $88^{\circ}$ del Código de Procedimiento Civil, toda vez que esta norma recibe aplicación supletoria en los juicios del trabajo.

Finalmente, las causales contempladas para el recurso de revisión de una sentencia firme, son plenamente aplicables a una causa laboral.

\section{CONCLUSION}

Las razones que explican que los principios formativos del procedimiento adquieren en sede laboral matices especiales, las encontraremos en la identidad más profunda del derecho sustantivo del trabajo, que se sustenta sobre datos y antecedentes históricos y

\footnotetext{
154 La experiencia indica que incluso la gestión oral del artículo 480 del Código de Procedimiento Civil se tramita con excesiva latitud, con el procedimiento establecido para los incidentes escritos.

155 Ver artículo 724 del Código de Procedimiento Civil.

${ }^{156}$ Ver artículo 88 del Código de Procedimiento Civil.

157 Ver artículo 810 del Código de Procedimiento Civil.
} 
principios jurídicos que le son característicos y esenciales, y que justifican su relativa autonomía respecto de otras disciplinas del derecho.

En efecto, el principal de estos matices, a nuestro juicio, es el carácter tutelar que reviste el ordenamiento jurídico-laboral, y que se expresa, en lo sustantivo, en el establecimiento de condiciones cualitativamente mínimas que regirán las relaciones entre empleadores y trabajadores, elevadas por el ordenamiento jurídico a la categoría de orden público, complementadas con una serie de mecanismos de protección a la persona y a las remuneraciones o beneficios del trabajador; y en lo adjetivo, se expresa en la vigencia de los principios de celeridad y concentración de los procedimientos, restricción en el alzamiento, imperio de la verdad real por sobre la verdad formal, traducido esto último en la amplitud del catálogo de medios probatorios y de las medidas para mejor resolver, en los sistemas de apreciación de la prueba conforme a las reglas de la sana crítica o de íntima convicción, según se trate del procedimiento de aplicación general o el de menor cuantía, en la acentuada presencia de la oficialidad, en la tendencia universal a la magistratura especializada, etc.

Un elemento de vital importancia que es menester tener presente para el entendimiento de esta disciplina es el carácter ético del vínculo jurídico entre trabajador y empleador que, desde luego, requiere un sistema normativo acorde a dicho carácter que, siendo una característica de la norma substantiva, debe ser recogida por la norma procedimental para prestar un buen servicio al derecho de fondo.

Siguiendo la doctrina moderna de nuestro mundo occidental, entendemos que el contrato de trabajo da origen a una relación de comunidad jurídico personal, que no se agota en la existencia y cumplimiento de obligaciones patrimoniales. El pago de la prestación a que se obliga el trabajador, esto es, prestar el trabajo convenido, compromete a su propia persona singular, sus fuerzas físicas e intelectuales, que emanan de su cuerpo. Por otro lado, la relación contractual no constituye un negocio fugaz y circunstancial, como podría pensarse de una relación mercantil, sino que de ella emanan y se desarrollan vínculos personales y duraderos. Ante este panorama, por parte del empleador, también pesa la obligación de humanizar sus prestaciones.

A la hora de regular el derecho la manera en que van a solucionarse los conflictos jurídicos entre trabajadores y empresarios, se requiere de un sistema especial, nutrido de los principios formativos del procedimiento, de la manera como -mas o menos- impera en el resto de los países occidentales que han adquirido una cierta y deseable evolución jurídica y política, de manera de recoger tales principios y adecuarlos a nuestra realidad jurídica, y proyectarlos como instrumento de verdadera paz social y de desarrollo económico. 